archives-ouvertes

\title{
Efficacy of acetylleucine in vertigo and dizziness: a systematic review of randomised controlled trials
}

Paul Vanderkam, Clara Blanchard, Florian Naudet, Denis Pouchain, Hélène

Vaillant Roussel, Marie Christine Perault-Pochat, Nematollah Jaafari, Rémy

Boussageon

\section{To cite this version:}

Paul Vanderkam, Clara Blanchard, Florian Naudet, Denis Pouchain, Hélène Vaillant Roussel, et al.. Efficacy of acetylleucine in vertigo and dizziness: a systematic review of randomised controlled trials. European Journal of Clinical Pharmacology, Springer Verlag, In press, 75 (5), pp.603-607. 10.1007/s00228-018-02617-6 . hal-01986731

\section{HAL Id: hal-01986731 \\ https://hal.archives-ouvertes.fr/hal-01986731}

Submitted on 19 Jan 2019

HAL is a multi-disciplinary open access archive for the deposit and dissemination of scientific research documents, whether they are published or not. The documents may come from teaching and research institutions in France or abroad, or from public or private research centers.
L'archive ouverte pluridisciplinaire HAL, est destinée au dépôt et à la diffusion de documents scientifiques de niveau recherche, publiés ou non, émanant des établissements d'enseignement et de recherche français ou étrangers, des laboratoires publics ou privés. 


\title{
Efficacy of acetylleucine in vertigo and dizziness: a systematic review of randomised
}

\author{
controlled trials
}

\author{
Order of authors : Paul VANDERKAM, Clara BLANCHARD, Florian NAUDET, Denis POUCHAIN, Helene \\ VAILlANT ROUSSEL, Marie Christine PERAUlt-POCHAT, Nematollah JAAFARI, Rémy \\ BOUSSAGEON
}

Affiliations :

Paul Vanderkam : Department of General Medicine, University of Poitiers, 6 rue de la Milétrie, TSA 51115, 86073 POITIERS Cedex 9. ORCID: 0000-0002-3603-5710

Clinical research unit, Henri Laborit Hospital, 370 av. Jacques cœur, CS 10587, 86021 Poitiers

Clara Blanchard : Department of General Medicine, University of Poitiers, 6 rue de la Milétrie, TSA 51115, 86073 POITIERS Cedex 9. ORCID: 0000-0001-9007-6954

Florian Naudet : Univ Rennes, CHU Rennes, Inserm, CIC 1414 (Clinical Center of investigation, Rennes), F-35000

Rennes, France. ORCID : 0000-0003-3760-3801

Denis Pouchain : Department of General Medicine, University of of Tours, 10 boulevard Tonnelé, BP 3223, 37032 Tours Cedex 1. ORCID: 0000-0001-6882-3474.

Hélène Vaillant-Roussel : Department of General Medicine and UPU ACCePPT, University of Auvergne ClermontFerrand Cedex 1, France28 place Henri Dunant, BP 38, 63001 CLERMONT-FERRAND Cedex 1. ORCID:

0000-0002-3384-0335

Marie-Christine Perault-Pochat : Clinical pharmacology and awareness department, University Hospital of Poitiers, 2 rue de la Milétrie, BP 577, 86021 POITIERS Cedex. ORCID: 0000-0002-3289-5502

Nematollah JAAFARI : CNRS 3557, CIC-P 1402 and clinical research unit, Henri Laborit Hospital, 370 av. Jacques cœur, CS 10587, 86021 Poitiers

Rémy Boussageon: $\quad$ UMR 5558, Laboratoire de Biométrie et Biologie Evolutive, Claude-Bernard Lyon 1 University, CNRS, Lyon, France.

\section{Corresponding author: Paul VANDERKAM}

Email : paul.vanderkam@univ-poitiers.fr - Phone number : +33549453333 


\begin{abstract}
Purpose : To assess the efficacy of acetylleucine to improve or stop an attack of vertigo and dizziness (vertigo/dizziness).

Methods : Systematic review by 2 independent reviewers. Consultation of the Medline, Cochrane and ClinicalTrials.gov databases until September 2018. Key words: Acetylleucine, Tanganil ${ }^{\circledR}$, Acetyl-DLleucine, Acetyl-leucine were used. Trial selection: Randomised controlled trials (RCTs) comparing Acetylleucine against placebo.

Results : Up till 2018, no RCTs have been published on the efficacy of acetylleucine in vertigo/dizziness

Conclusion : There is no solid evidence of the efficacy of acetylleucine in vertigo/dizziness. Given its frequent prescription and the cost generated for the French social security system, high-quality randomised trials should be carried out to assess its efficacy.
\end{abstract}

\title{
$\underline{\text { Keywords }}$
}

Acetylleucine - Dizziness - Randomised controlled trial - Treatment outcome-Vertigo 


\section{Introduction}

Dizziness is a general term for a sense of disequilibrium. Vertigo is a subtype of dizziness, defined as an illusion of movement which results in an impression of rotation or false movement [1]. It often occurs along with neurovegetative signs (nausea or vomiting), nystagmus and a tendency to fall without loss of consciousness during the attack $[2,3]$.

In general medicine and emergency medicine, vertigo and dizziness have a lifetime prevalence of between 20 and $30 \%$ [4-7] with an annual incidence of about $11 \%$ [8]. These symptoms are also the single most frequent complaint among patient older than 75 years [9-11]. In primary care, up to $10 \%$ of all adults consult a physician because of vertigo $[8,12]$.

Vertigo and dizziness have various aetiologies caused by physiological irritation (rotatory vertigo, motion sickness, visual height intolerance) or a pathological lesion (unilateral labyrinthine failure or vestibular nuclei lesion). Vertigo is either vestibular or neurological (transient ischaemic attack (TIA) or cerebellar stroke) and dizziness covers broader symptoms: vertiginous sensations, drunkenness or faintness attacks which are the result of cardiovascular (vasovagal, orthostatic hypotension), metabolic or psychological disorders [1].

In out-patient, cases seen by general practitioners, the most frequent four causes, accounting for about $90 \%$ of cases, are benign paroxysmal positional vertigo (BPPV), vestibular neuritis (sudden idiopathic or viral unilateral vestibular deficit), vestibular migraine and Menière's disease [11-13]. Indeed, half of the cases of dizziness is associated to anxiety disorders [13].

In France, Acetylleucine $\left(\right.$ Tanganil $\left.^{\circledR}\right)$ is often prescribed to treat attacks of vertigo, whether in general practice clinics or in emergency wards. Its pharmacodynamics are not fully understood. The hypothesis is that it restores the membrane potential [14-16], via an interaction with membrane phospholipids on the injured side of vestibular neurons mainly in the thalamus or parietal region of the cortex [17].The reimbursement rate of this drug is decided by a committee of experts who in 2016 concluded that it had a moderate medical effect and decided on a $30 \%$

reimbursement rate $[18,19]$. Consequently, according to data from the social security's financial branch (Caisse nationale de l'assurance maladie des travailleurs salaries; CNAMTS), acetylleucine cost about 6 million euros in 2016 (Table 1) [20]. 
Considering this cost, and to evaluate the efficacy of the acetylleucine to treat vertigo and dizziness

(vertigo/dizziness), a systematic review was carried out in the hope that data could be meta-analysed to answer the question of its efficacy.

\section{Materials and method}

\section{Main objective}

The main objective was to evaluate the clinical efficacy of acetylleucine to reduce or stop attacks of vertigo/dizziness.

\section{Research methodology}

A systematic review, following the PRISMA statement [21], was carried out by searching the main free-access databases up to the 15th of September 2018: Medline, Cochrane Central and the American database for recording clinical trials (ClinicalTrials.gov). Keywords used to find each of three drugs available were: "Acetylleucine" or "Tanganil ${ }^{\circledR "}$ or "Acetyl-DL-Leucine" or "Acetyl-leucine".

\section{Eligibility criteria}

Randomized controlled clinical trials versus placebo with double blinding were included. Trials were included if the full-text was available in English or in French. The trials had to evaluate the clinical efficacy of the drug acetylleucine.

All causes or types of vertigo and dizziness were included and trials were included regardless of their duration. Assessment criteria

The primary endpoint was the significant improvement (or the disappearance) of vertigo/dizziness between baseline and the end of the trial.

\section{Trial selection}

Two reviewers collected data for primary endpoint and data to assess trial quality and recorded it on separate spreadsheets. 
The qualitative analysis was based on the data collected. A quantitative analysis using Revman $5.3^{\circledR}$ was planned with calculation of the relative risk expressed with a confidence interval of $95 \%$ (significance $\mathrm{p}<0.05 \%$ ) according to the model of Mantel-Haenszel (because the hypothesis was that the trials would be very heterogeneous).

\section{Results}

The flow chart is presented in fig. 1.

The systematic review did not find any articles that met the inclusion criteria chosen for this review.

No randomised clinical trial, comparative, even with active comparator was found. Other trials were preclinical or observational in patients with cerebellar ataxia (Fig. 1).

\section{Discussion}

The main finding of this systematic review of the literature is the total lack of evaluation of the efficacy of acetylleucine. The search equation used did not find any randomised controlled clinical trial evaluating the efficacy of acetylleucine for vertigo although intermediate outcomes were considered, all trial durations and all types of vertigo/dizziness. It is possible that this review missed trials from unpublished or unreferenced databases. No trial was excluded because it was not available in English or French. However, the search did find an observational study available only in Italian. It was published in 1960 and apparently found promising results in favour of acetylleucine in patients with vertigo/dizziness, but the methodology was not available for critical review. [22] (Fig. 1).

Even though, clinical trials on animals showed an improvement in locomotor balance after forced rotation or unilateral vestibular neurotomy [15,16,22-24]. This review confirms the findings, 16 years after its publication, of a review by Neuzil [14] which also did not find any randomised clinical trial evaluating acetylleucine since its first launch on the market in the 1950 s.

One clinical trial identified in the database search was a randomised controlled trial but was not included because of a particular study-design. It included 52 patients who underwent vestibular neurotomy to treat either an evolved form of Meniere disease or a neurinoma of the acoustic nerve. This study found that there was no significant improvement of dizziness in the group who received acetylleucine in comparison with the control group who underwent the surgery without any other treatment [9]. Another clinical trial which was carried out without randomisation but with blinding of participants found no improvement of vertiginous symptoms. In another clinical trial with double 
blinding but without randomisation, no improvement of symptoms was found after vestibular training of 20 healthy patients in comparison to the control group who only had vestibular training and placebo treatment [25]. In two series of case-studies, significant improvement in Scale for the assessment and rating of ataxia (SARA) from baseline was observed in patients with cerebellar ataxia after 1 week [26] and 5 weeks [27] of acetylleucine treatment. A significant improvement of SARA score and quality of life was also noted on 12 patients with Niemann-Pick disease class $\mathrm{C}$ after 1 month of acetylleucine administration [28]. A randomised and placebocontrolled clinical trial testing acetylleucine in cerebellar syndrome (ALCAT) is currently underway and could provide more evidence $[29,30]$.

In parallel, a recent Cochrane meta-analysis [31] on betahistine, another frequently prescribed anti-vertigo treatment, also concluded to insufficient clinical evidence. The included trials were heterogeneous and the level of evidence was poor (low number of participants, old trials) [31]. Moreover, this review did not include a recent randomized trial evaluating betahistine in Meniere disease [32]. In this trial, the primary endpoint (number of vertigo attacks) did not significantly decrease, whether with low or with high dosages $(p=0.76)$. For vestibular neuritis, a 2011 meta analysis showed a significant effect of cortico steroid at 1 month but not at the end of 12 month follow up [33].

At present, vestibular rehabilitation has clinically proven efficacy with a good level of evidence and is therefore the treatment of choice for patients with vestibular dysfunction. [34]. For BPPV, Espley manoeuvre allows significant improvement of vertigo symptoms [35].

Despite the lack of clinical evaluation and the diverging results of available trials, the Transparency Committee in France continues to recommend the reimbursement of acetylleucine for the treatment of vertigo at a dose of $500 \mathrm{mg}$ to $2000 \mathrm{mg}$ per day in both its 2011 and 2016 re-evaluations of this drug [19]. Consequently, it is a frequently prescribed treatment as shown in a survey of 171 teaching supervisors and 305 interns in general medicine from 4 universities. $93 \%$ of respondents had already prescribed acetylleucine for vertigo, but only half of them knew that there was insufficient evidence of its efficacy [36].

As the benefit is questionable at best, the risks must be considered. Acetylleucine is known to cause only very rare adverse effects such as skin rash (with or without pruritus) and urticaria [37]. The risk is low in case of overprescription. Acetylleucine is an unassessed drug and until proven otherwise can be considered as an impure placebo [38]. Indeed, it has established pharmacological effects but clinical efficacy is not sufficiently assessed. 
The question of drug efficacy is an important one. In 2010, an American study [39] including 412 general practitioners showed that $56 \%$ of them reported using placebo treatments in their practice, impure in $89 \%$ of cases. Using such treatments may seem harmless, but this attitude encourages over-treatment, as a patient comes to expect a drug for each ailment. Moreover, the use of impure placebos raises an ethical dilemma because, unlike pure placebos, these pharmacologically active substances can cause adverse effects. How can the practitioner decide between the unknown benefits and the possible risks associated with this kind of prescription?

\section{Conclusion}

Acetylleucine has a marketing authorisation and is reimbursed in France in the symptomatic treatment of vertigo/dizziness although there is no evidence of its efficacy. Due to its frequent prescription and considering the cost supported by the national healthcare system, randomised trials of high quality specifically carried out to measure the efficacy of this drug seem indispensable. Until sufficient data is gathered, evidence-based minded clinicians should remember that it is at best an impure and a costly placebo.

\section{CONTRIBUTIONS OF AUTHORS}

Paul Vanderkam: performed the research, analysed the data and wrote the paper.

Clara Blanchard: contributed to the writing of the paper and the data analysis.

Florian Naudet: contributed to the writing of the paper.

Denis Pouchain: contributed to the writing of the paper.

Marie-Christine Perrault-Pochat: contributed to the writing of the paper.

Hélène Vaillant-Roussel: contributed to the writing of the paper.

Nematollah Jaafari: contributed to the writing of the paper.

Remy Boussageon: conceived the study and analysed the data. 


\section{REFERENCES}

1. Sloane PD (2001) Dizziness: State of the Science. Annals of Internal Medicine 134:823. https://doi.org/10.7326/0003-4819-134-9_Part_2-200105011-00005

2. Adams RD, Victor M, Ropper AH (1997) Principles of Neurology, 6th edn. McGraw-Hill, Health Professions, pp300-1

3. Hanley K, O' Dowd T (2002) Symptoms of vertigo in general practice: a prospective study of diagnosis. Br J Gen Pract 52: 809-12

4. Brandt T, Dieterich M, Strupp M (2013) Vertigo and Dizziness: Common Complaints, 2nd ed. Springer-Verlag, London

5. Karatas M (2008) Central Vertigo and Dizziness: Epidemiology, Differential Diagnosis, and Common Causes. The Neurologist 14:355. https://doi.org/10.1097/NRL.0b013e31817533a3

6. Royl G, Ploner CJ, Möckel M, Leithner C (2010) [Neurological chief complaints in an emergency room]. Nervenarzt 81:1226-1230. https://doi.org/10.1007/s00115-010-3020-X

7. Sloane PD (1989) Dizziness in primary care. Results from the National Ambulatory Medical Care Survey. J Fam Pract 29:33-38

8. Corrales CE, Bhattacharyya N (2016) Dizziness and death: An imbalance in mortality. The Laryngoscope 126:2134-2136. https://doi.org/10.1002/lary.25902

9. Chawla N, Olshaker JS (2006) Diagnosis and Management of Dizziness and Vertigo. Med Clin North Am 90:291-304. https://doi.org/10.1016/j.mcna.2005.11.003

10. Neuhauser HK, von Brevern M, Radtke A, Lezius F, Feldmann M, Ziese T, et al. (2005) Epidemiology of vestibular vertigo: a neurotologic survey of the general population. Neurology 65(6):898-904. https://doi.org/10.1212/01. wnl.0000175987.59991.3d

11. Neuhauser HK (2016) Chapter 5 - The epidemiology of dizziness and vertigo. In: Furman JM, Lempert T (eds) Handbook of Clinical Neurology. Elsevier, pp 67-82

12. Rieger A, Mansmann U, Maier W, et al (2014) [Management of patients with the cardinal symptom dizziness or vertigo]. Gesundheitswesen 76:e32-38. https://doi.org/10.1055/s-0033-1357145 
13. Kroenke K, Lucas CA, Rosenberg ML, Scherokman B, Herbers JE, Wehrle PA, et al. (1992) Causes of Persistent Dizziness: A Prospective Study of 100 Patients in Ambulatory Care. Ann Intern Med 117:898-904. https//doi.org/10.7326/0003-4819-117-11-898

14. Neuzil E, Ravaine S, Cousse H (2002) La N-acetyl-DL-leucine, médicament symptomatique des états vertigineux. Bulletin de la société de pharmacie de Bordeaux 141:15-38

15. Vibert N, Vidal PP (2001) In vitro effects of acetyl-DL-leucine (Tanganil) on central vestibular neurons and vestibulo-ocular networks of the guinea-pig. Eur J Neurosci 13:73548. https://doi.org/10.1046/j.0953816x.2000.01447.x

16. Ferber-Viart C, Dubreuil C, Vidal PP (2009) Effects of acetyl-DL-leucine in vestibular patients: a clinical study following neurotomy and labyrinthectomy. Audiol Neuro-otol 14:1725. https://doi.org/10.1159/000148206

17. Becker-Bense S, Feuerecker R, Xiong G, et al (2015) P37. Effects of acetyl-dl-leucine on the cerebral activation pattern in cerebellar ataxia (FDG-PET study). Clinical Neurophysiology 126:e115. https://doi.org/10.1016/j.clinph.2015.04.175

18. Commission de la Transparence HAS - avis du 6 juillet 2011: Tanganil@. http://www.hassante.fr/portail/upload/docs/application/pdf/2011-07/tanganil_-_ct-9859.pdf. Accessed 19 november 2016.

19. Commission de la Transparence HAS - avis du 9 novembre 2016: Tanganil®. http://www.hassante.fr/portail/upload/docs/evamed/CT-14961_TANGANIL-TANGANILPRO_PIS_RI_Avis1_CT14961.pdf. Accessed 1st december 2016

20. Medic'AM (2018) Données mensuelles et annuelles sur les médicaments remboursés par l'Assurance Maladie en 2017. Ameli. https://www.ameli.fr/l-assurance-maladie/statistiques-et-publications/donneesstatistiques/medicament/medic-am/medic-am-mensuel-2018.php. Accessed 1st october 2018

21. Liberati A, Altman DG, Tetzlaff J, Mulrow C, Gøtzsche PC, Ioannidis JPA, et al. (2009) The PRISMA Statement for Reporting Systematic Reviews and Meta-Analyses of Studies That Evaluate Health Care Interventions: Explanation and Elaboration. PLoS Med 6(7):e1000100. https://doi.org/10.1371/journal.pmed.1000100

22. Chinellato F (1960) Experimental research on the behavior of vestibular function after the administration of certain drugs. II. Acetyl-DL-leucine. Boll Soc Ital Biol Sper 36:112830 
23. Günther L, Beck R, Xiong G, Potschka H, Jahn K, Bartenstein P, et al. (2015) N-acetyl-L-leucine accelerates vestibular compensation after unilateral labyrinthectomy by action in the cerebellum and thalamus. PLoS ONE 10: e0120891. https://doi.org/10.1371/journal.pone.0120891

24. Platt F, Strupp M (2016) An anecdotal report by an Oxford basic neuroscientist: effects of acetyl-DL-leucine on cognitive function and mobility in the elderly. J Neurol 263:123940. https://doi.org/10.1007/s00415-016-8048-9

25. Clément G, Deguine O, Bourg M, Pavy-LeTraon A (2007) Effects of vestibular training on motion sickness, nystagmus, and subjective vertical. J Vestib Res 17: 22737.

26. Strupp M, Teufel J, Habs M, Feuerecker R, Muth C, van de Warrenburg BP, et al. (2013) Effects of acetyl-DLleucine in patients with cerebellar ataxia: a case series. J Neurol 260:255661. https://doi.org/10.1007/s00415-0137016-X

27. Schniepp R, Strupp M, Wuehr M, Jahn K, Dieterich M, Brandt T, et al. (2016) Acetyl-DL-leucine improves gait variability in patients with cerebellar ataxia-a case series. Cerebellum Ataxias 3:8. https://doi.org/10.1186/s40673016-0046-2

28. Bremova T, Malinová V, Amraoui Y, et al (2015) Acetyl-dl-leucine in Niemann-Pick type C: A case series. Neurology 85:1368-1375. https://doi.org/10.1212/WNL.0000000000002041

29. Feil K, Adrion C, Teufel J, et al (2017) Effects of acetyl-DL-leucine on cerebellar ataxia (ALCAT trial): study protocol for a multicenter, multinational, randomized, double-blind, placebo-controlled, crossover phase III trial. BMC Neurol 17:7. https://doi.org/10.1186/s12883-016-0786-x

30. Feil K, Bremova T, Muth C, et al (2016) Update on the Pharmacotherapy of Cerebellar Ataxia and Nystagmus. The Cerebellum 15:38-42. https://doi.org/10.1007/s12311-015-0733-1

31. Hussain K, Schilder AG (2016) Betahistine for symptoms of vertigo. Cochrane Database Syst Rev 21;6:CD010696. https://doi.org/0.1002/14651858.CD010696.pub2

32. Adrion C, Fischer CS, Wagner J, Gürkov R, Mansmann U, Strupp M, BEMED Study Group (2016) Efficacy and safety of betahistine treatment in patients with Meniere's disease: primary results of a long term, multicentre, double blind, randomised, placebo controlled, dose defining trial (BEMED trial). BMJ 352:h6816. https://doi.org/ 10.1136/bmj.h6816 
33. Fishman JM, Burgess C, Waddell A (2011) Corticosteroids for the treatment of idiopathic acute vestibular dysfunction (vestibular neuritis). Cochrane Database Syst Rev CD008607. https://doi.org/10.1002/14651858.CD008607.pub2

34. McDonnell MN, Hillier SL (2015) Vestibular rehabilitation for unilateral peripheral vestibular dysfunction. Cochrane Database Syst Rev 1:CD005397. https://doi.org/10.1002/14651858.CD005397.pub4

35. Hilton MP, Pinder DK (2014) The Epley (canalith repositioning) manoeuvre for benign paroxysmal positional vertigo. Cochrane Database Syst Rev 12:CD003162. https://doi.org/10.1002/14651858.CD003162.pub3

36. Boussageon R., Foucher E., Huas C (2017) Connaissances des médecins généralistes sur l'efficacité de sept médicaments courants : Enquête par questionnaire. Médecine 13:205-210.

37. ANSM. Notice patient Tanganil. ANSM. $2018 . \quad$ http://agenceprd.ansm.sante.fr/php/ecodex/notice/N0274438.htm. Accessed 15 december 2018

38. Louhiala P, Hemilä H, Puustinen R (2015) Impure placebo is a useless concept. Theor Med Bioeth. 36(4):279- 89. https://doi.org/10.1007/s11017-015-9336-6

39. Hasham I (2010) Family Physicians Believe the Placebo Effect Is Therapeutic But Often Use Real Drugs as Placebos. Family Medicine 42:636-42 
Table 1 Prescriptions and reimbursement of acetylleucine in France in 2017

\begin{tabular}{|l|c|c|}
\hline & $\begin{array}{c}\text { Number of boxes } \\
\text { reimbursed (30 pills) }\end{array}$ & Reimbursed amount (€) \\
\hline Acetylleucine & 4926023 & 5713701 \\
\hline
\end{tabular}

Fig. 1 Flow Chart

Figure Caption 